\title{
IMPACTOS DA CRISE ECONÔMICA SOBRE O SETOR DE SERVIÇOS NO ESPÍRITO SANTO: UMA ANÁLISE DE 2012 A 2017
}

\author{
Neilessandra da Silva ${ }^{1}$ \\ José Claudio Tardin Tavares Negris ${ }^{2}$ \\ Flávio Raposo Pereira ${ }^{3}$
}

\begin{abstract}
Resumo
O objetivo deste estudo consistiu em verificar os impactos da crise econômica no setor de serviços no estado do Espírito Santo. Foram utilizados como base de dados os resultados da Pesquisa Mensal de Serviços (PMS), realizada pelo Instituto Brasileiro de Geografia e Estatística (IBGE). Desta forma, foram levantadas informações a fim de estabelecer se há uma queda dos indicadores que pode ser relacionada com a atual crise econômica brasileira que se iniciou em 2015. Os resultados obtidos revelaram que houve uma diminuição acentuada no nível de serviços no estado, com variações negativas tanto na receita nominal de serviços como no volume de serviços, impactando diretamente no número de empregos formais gerados pelo setor, atingindo saldo líquido de -30.162 entre os anos de 2015 e 2016.
\end{abstract}

Palavras-chave: Setor de Serviços. Espírito Santo. Crise econômica.

\section{IMPACTS OF THE ECONOMIC CRISIS ON THE SERVICE SECTOR IN ESPÍRITO SANTO: AN ANALYSIS FROM 2012 TO 2017}

\begin{abstract}
The objective of this study was to verify the impacts of the economic crisis on the services sector in Espírito Santo. The results of the Monthly Service Survey (PMS), performed by the Brazilian Institute of Geography and Statistics (IBGE), were used as a database. Thus, information was collected in order to establish if there is a drop in the indicators that may be related to the current Brazilian economic crisis that began in 2015. The results showed that there was a marked decrease in the level of services in the state, with negatives variations in the nominal service revenue and service volume. This generated a directly impact in the number of formal jobs generated by the sector, inflicting the net balance of $-30,162$ between the years of 2015 and 2016.
\end{abstract}

Keywords: Service Sector. Espírito Santo. Economic crisis.

1 Graduanda em Engenharia de Produção pelo Ifes, Campus Cariacica. E-mail: neilessandra@ @otmail.com.

2 Graduando em Engenharia Ambiental pela Ufes, Campus Goiabeiras. E-mail: jonegris@gmail.com.

3 Graduado em Engenharia de Produção, Pós-graduado em gestão da qualidade, Mestre em engenharia e desenvolvimento sustentável. Professor do Ifes, Campus Cariacica. E-mail: flavio.pereira@ifes.edu.br. 


\section{INTRODUÇÃO}

É indiscutível que diversos países passam por processos de transformação estrutural, principalmente no que se refere à sua dinâmica nas esferas econômica, política, social, tecnológica, científica e cultural.

Essas transformações têm como uma de suas consequências o deslocamento da geração de renda e de emprego através dos setores da economia. Nota-se que esse deslocamento tem início na agricultura, passa pela indústria e avança rumo ao setor de serviços.

No Brasil essa mudança estrutural em direção ao setor terciário vem ocorrendo desde os anos 50 e fica cada vez mais evidente, uma vez que o setor de serviços é responsável, atualmente, por mais de $70 \%$ de participação no Produto Interno Bruto (PIB) do país. Entre 2007 e 2013, por exemplo, houve um aumento nos principais indicadores envolvendo o setor, entre eles o crescimento de $58 \%$ no número de empresas (média de $8 \%$ ao ano) e o aumento de 50\% no número de pessoal ocupado (SILVA, FILHO e KOMATSU, 2016).

Por se tratar de um setor tão importante para a economia brasileira, o terciário foi um dos mais afetados com a crise econômica iniciada em 2015 e que ainda perdura sobre o país.

Esta instabilidade econômica foi desencadeada por uma série de fatores, mais ou menos simultâneos, dos quais se pode destacar: o crescimento da crise econômica internacional e seus efeitos sobre o Brasil; as eleições acirradas com fortalecimento da oposição ao governo; a ampliação da crise política ocasionada por denúncias de corrupção envolvendo políticos ligados ao governo; o descontrole político e desestabilização de alianças políticas que apoiavam o governo vigente; e a insatisfação e revolta popular contra as medidas de ajuste fiscal tomadas pelo governo (ANTUNES, 2015).

Com o agravamento da crise, em setembro de 2015 o Brasil teve sua nota de crédito rebaixada pela agência de classificação de risco Standard \& Poor's, o que indica risco para investidores (PIGNATA e CARVALHO, 2015).

Não obstante, o país registrou um PIB negativo em 2015 (-3,6\%). No mesmo ano a taxa de inflação atingiu 10,7\%, maior índice desde 2002. O péssimo desempenho se repetiu na produção industrial, agropecuária e infraestrutura, além do aumento na taxa de desemprego (DIEESE, 2016). 
Mergulhado neste profundo período de recessão, o setor de serviços no Brasil apresentou uma queda acumulada de 3,7\% entre fevereiro de 2015 e fevereiro de 2016 . Porém, o baixo desempenho foi ainda maior no estado do Espírito Santo, onde a diminuição do volume de serviços foi de $6,1 \%$ no mesmo período (IBGE, 2017b).

O setor de serviços caracteriza-se como a principal atividade econômica do estado do Espírito Santo, representando 56,3\% do PIB estadual, além da relevante contribuição na geração de emprego. No ano de 2013, por exemplo, o setor empregava 253.275 pessoas (IBGE, 2017a).

Para o estudo, foram utilizados dados da Pesquisa Mensal de Serviços - PMS, realizada pelo Instituto Brasileiro de Geografia e Estatística - IBGE, englobando o período de janeiro de 2012 a maio de 2017. Através da análise das informações sobre receita do setor, pessoas empregadas e participação no mercado, foi possível fazer um levantamento dos principais efeitos sobre a economia capixaba.

O tema abordado tem sua relevância prática e intelectual, visto que o setor de serviços é importante para a economia capixaba e o estudo contribui para a compreensão dos impactos nele causados pela atual crise econômica. Deve-se ressaltar também que apesar de o tema proposto estar muito em evidência ultimamente, ele não é amplamente abordado pela literatura, sendo tratado, na maioria das vezes, apenas como uma apresentação de dados independentes, sem qualquer análise mais aprofundada. Dessa forma, o presente trabalho propõe uma nova abordagem do tema, trazendo uma análise mais aprofundada dos indicadores de desempenho do setor de serviços a fim de verificar os impactos da recessão no Espírito Santo.

\section{REFERENCIAL TEÓRICO}

\subsection{O setor de serviços}

O setor de serviços, também chamado setor terciário, refere-se a todas as atividades econômicas que não produzem bens materiais, e, sim, prestam serviços às empresas e/ou aos consumidores finais (ALMEIDA, SILVA e ANGELO, 2013), sendo definido como a combinação dos resultados e experiências proporcionadas ao cliente e recebidas por ele (JOHNSTON e CLARK, 2011; JOHNSON, 2008). 
De acordo com Sambatti e Rissato (2003), estas atividades são classificadas como setor terciário pelo critério da exclusão dos dois outros setores (primário e secundário). Ou seja, toda atividade que não pode ser considerada como manufatura, construção civil, nem agricultura ou extrativismo é classificada como serviço.

De maneira simplificada os serviços podem ser classificados como operações "não agrícolas” e “não manufatureiras" que abrangem as atividades de transporte, comércio de mercadorias, comunicações, prestação de serviços e administração pública (MOURA e ALLIPRANDINI, 2004).

Para Fitzsimmons (2010), pode-se encontrar muitas definições de serviços, mas todas consideram a intangibilidade e a simultaneidade do consumo em diferentes graus como suas características. A intangibilidade dos serviços difere da relação que se estabelece com os produtos, e esse fato pode significar uma nova alternativa para a introdução de inovações constantes nas organizações (BATTAGLIA e BORCHARDT, 2010). Já a simultaneidade destaca-se pela produção e o consumo ocorrerem de maneira conjunta, em que os serviços não podem ser estocados e, como consequência, não há inspeção antes da entrega (FITZSIMMONS e FITZSIMMONS, 2005).

Além da intangibilidade e da simultaneidade, os serviços se caracterizam pelo fato de serem heterogêneos, intransferíveis, não estocáveis e por apresentarem um contato direto entre produtores e consumidores (SAMBATTI e RISSATO, 2003).

Ainda quanto às suas atividades, de acordo com Jonhson (2008), o setor de serviços inclui seguimentos como informação, finanças e seguro, imobiliário, profissional, serviços científicos e técnicos, gestão de empresas, apoio administrativo, educação, artes, entretenimento e recreação, serviço de alojamento e alimentação e serviços da administração pública. Já o IBGE (2011) classifica os segmentos do setor de serviços conforme as atividades dispostas no Quadro 1.

O setor de serviços é de grande importância na economia mundial atual, pois serve como facilitador das transações econômicas, assim como age como integrador das diversas atividades da economia (CARDOSO e ALMEIDA, 2013).

Este setor apresenta um comportamento diferenciado tanto em economias desenvolvidas como em desenvolvimento, demonstrando, em ambas, importância no desenvolvimento econômico e na 
geração de empregos (BASTOS, PEROBELLI e SOUZA, 2008; POP-FLOREA e HERMAN, 2009), devido à sua influência decisiva no crescimento, no emprego, na competitividade empresarial e no bem-estar da população (SIMBRACS, 2013).

\section{Quadro 1 - Segmentos do setor de serviços segundo o IBGE}

\begin{tabular}{|l|l|}
\hline \multicolumn{2}{|c|}{ SEGMENTOS DE ATIVIDADES } \\
\hline Serviços prestados às famílias; & $\begin{array}{l}\text { Serviços profissionais, administrativos } \\
\text { complementares; } \\
\text { Serviços de informação e comunicação; } \\
\text { Serviços de manutenção e reparo; }\end{array}$ \\
Atividades imobiliárias; & Outras atividades. \\
\hline
\end{tabular}

Fonte: IBGE (2011)

Para Bastos et al. (2008), o setor de serviços pode ser comparado à indústria em termos de produtividade e em capacidade de geração de emprego. Ainda segundo os autores, serviços e manufatura estão associados, pois a interação entre os dois setores promove o ganho de espaço pelos serviços, principalmente na absorção de profissionais não qualificados para a indústria e no fornecimento de conhecimento especializado.

Em relação à geração de empregos no Brasil, a Figura 1 mostra que o setor de serviços foi responsável por mais de 60\% dos empregos gerados no período de 2012 a 2016.

A tomar como exemplo, em 2013 cerca de 1,2 milhão de empresas prestadoras de serviços geraram $\mathrm{R} \$ 1,2$ trilhão em receita operacional líquida, empregaram 12,5 milhões de pessoas e pagaram aproximadamente R \$253,9 bilhões de reais em salários (IBGE, 2017c; 2017d).

Entre os segmentos do setor que mais empregam, destacam-se os serviços profissionais, administrativos e complementares, os serviços prestados às famílias, atividades de transporte, serviços auxiliares aos transportes e correio. De acordo com o IBGE (2014), em 2014 estas atividades atingiram juntas $78,7 \%$ de participação na receita operacional líquida, o que representou cerca de $\mathrm{R} \$ 1,1$ trilhão em receita naquele ano. 
ISSN 2359-4799

Figura 1 - Distribuição da população ocupada segundo os segmentos do setor de serviços (em \%) -

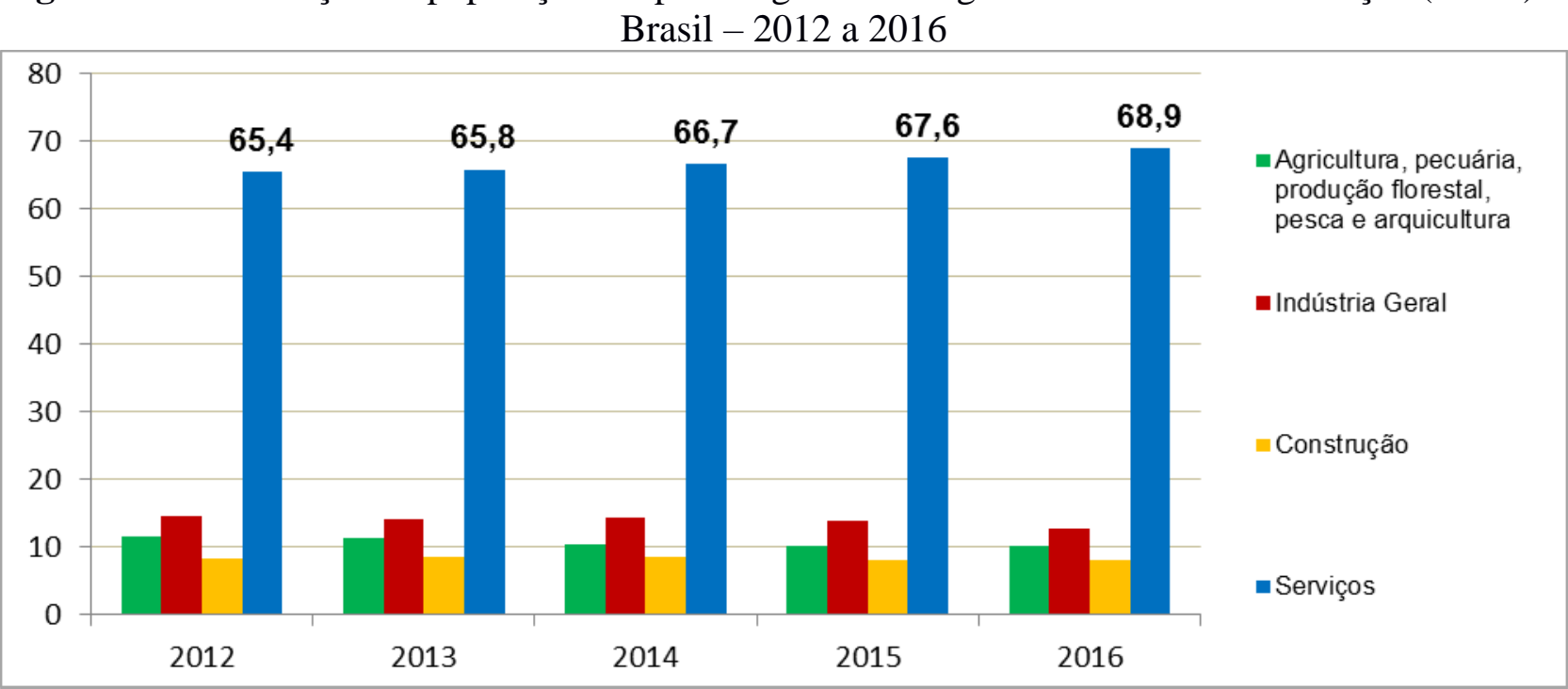

Fonte: IBGE (2017c)

Na Figura 2 a seguir, é possível observar o número de pessoas ocupadas por segmento de serviço no ano de 2014, totalizando 10,854 milhões de empregos no país.

Figura 2 - Número de pessoas ocupadas segundo o segmento de serviço (em mil) - Brasil - 2014

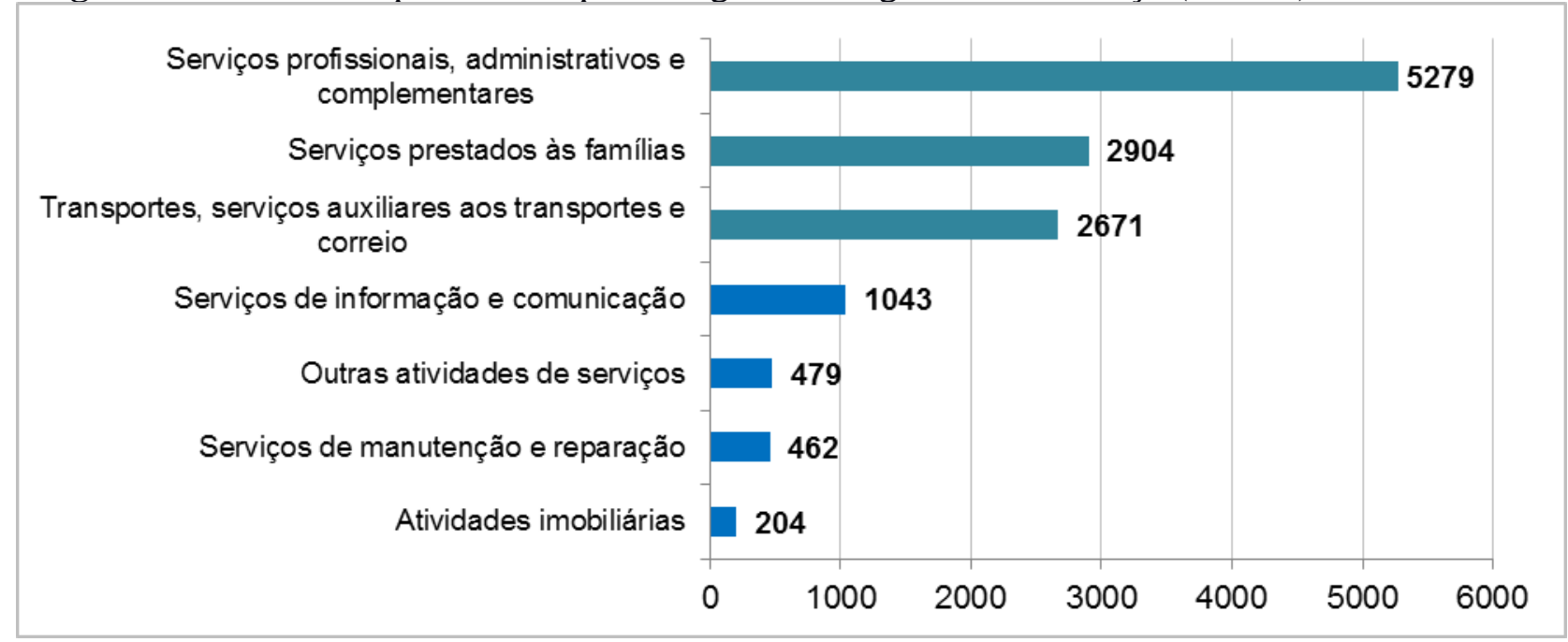

Fonte: IBGE (2014)

Ainda em termos de representatividade na economia brasileira, de acordo com o IBGE (2017a), no ano de 2015 o setor correspondia a 71,4\% do PIB nacional, com destaque para os subsetores de 
serviços de informação, de transporte, de armazenagem e correio e de comércio, que apresentaram os maiores avanços.

Conforme a Figura 3, não é de hoje que o setor de serviços tem significativa participação no PIB brasileiro, apresentando maior crescimento, principalmente a partir da década de 90.

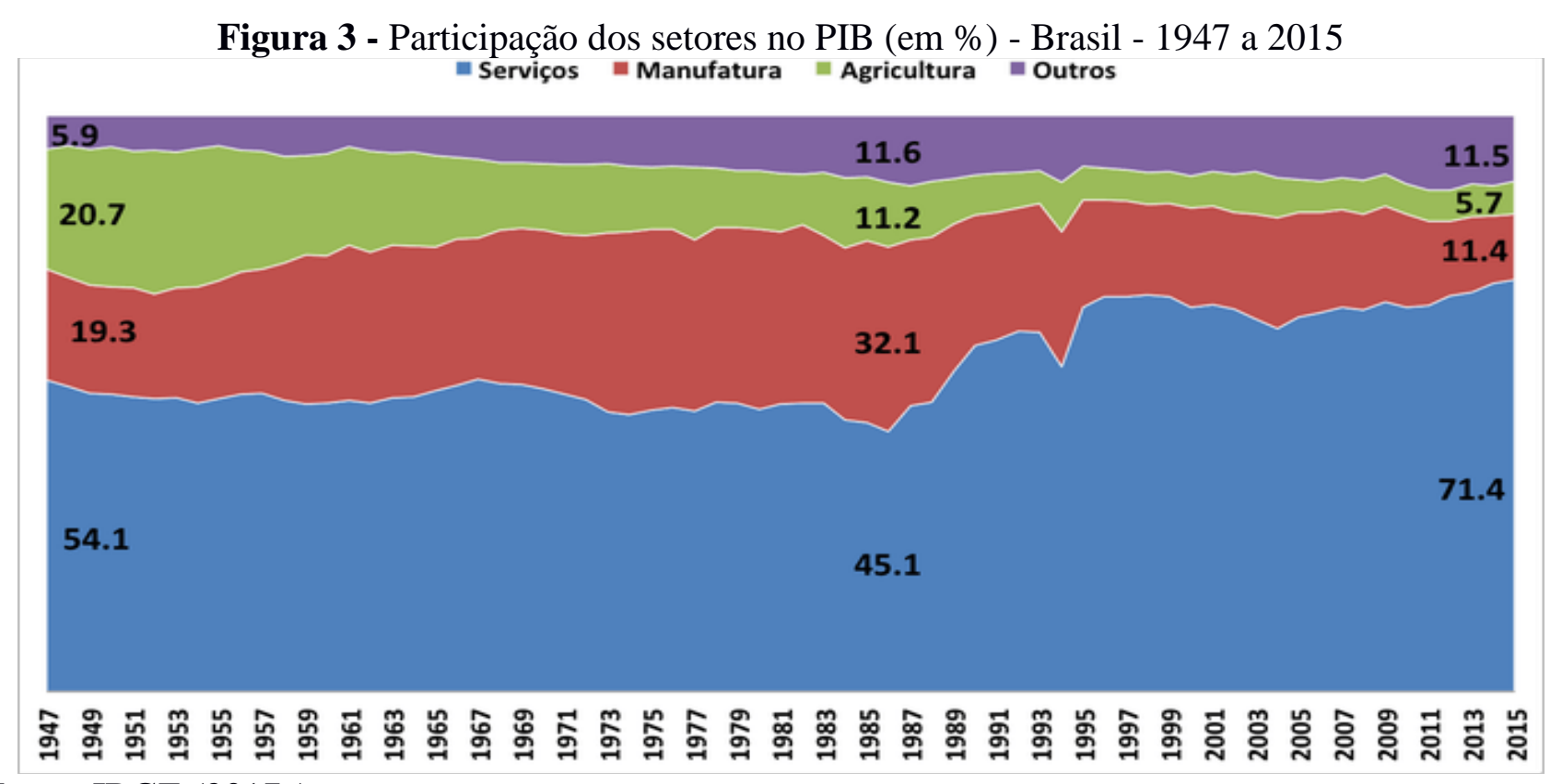

Fonte: IBGE (2017a)

Isso demonstra que além de ser responsável pela maior parcela do PIB, o setor de serviços se apresenta como parcela mais dinâmica da economia (CORREA e CAON, 2002).

Por apresentar grande importância na economia e ter sua qualidade medida através da percepção do cliente, tem-se que essa satisfação é afetada por muitos e, às vezes, até por todos os aspectos de uma organização de serviços (BATTAGLIA e BORCHARDT, 2010; JOHNSTON e CLARK, 2011; GUARDANI, TEIXEIRA, BIDO e MAZZON, 2013).

Por se tratar de um setor com alto grau de ligação e de influência na economia, alterações no cenário do setor de serviços podem impactar no cenário econômico e vice-versa.

Dentro deste contexto, pode-se ressaltar que se o setor de serviços tem um baixo desempenho, a economia tende a seguir o mesmo caminho, visto que este é o setor que mais emprega. Por 

consequência, acaba gerando demissão, resultando em menos consumo e em menos produção. Isso fica evidente na Figura 4, que mostra a taxa de crescimento anual do PIB e do PIB per capita.

Figura 4 - PIB e PIB per capita (em \%) - Brasil - 2000 a 2015

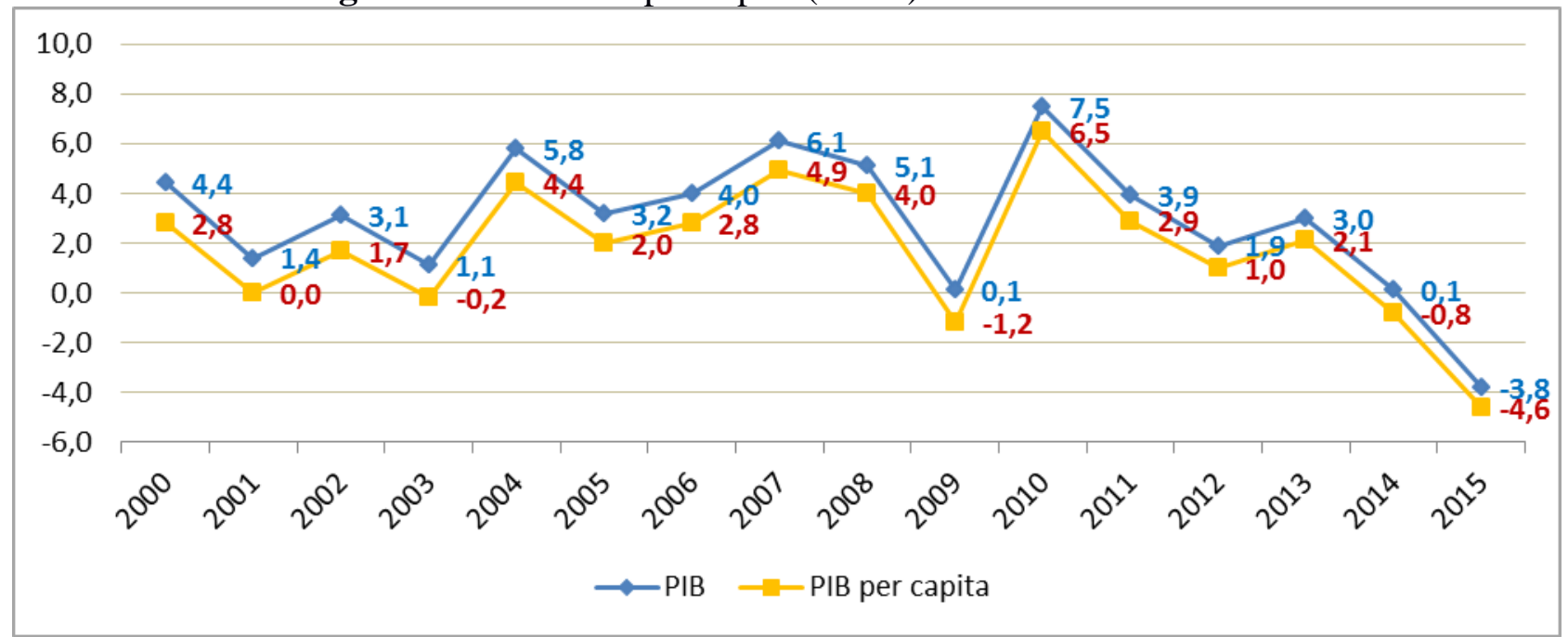

Fonte: IBGE (2017a)

De acordo com a Figura 4, em 2014 o PIB cresceu apenas 0,1\%, porém mesmo com este baixo desempenho, o setor de serviços conseguiu crescimento de $0,7 \%$ em relação ao ano anterior. Já em 2015 o PIB sofreu queda de 3,8\%, e o setor de serviços também apresentou queda significativa, cerca de $2,7 \%$ em relação a 2014 (IBGE, 2017a).

\subsection{A economia capixaba e o panorama do setor de serviços no estado do Espírito Santo}

Situado na região Sudeste, o Espírito Santo é o quarto menor estado do país, com uma área de 46.089,390 $\mathrm{Km}^{2}$. Apesar de sua pequena extensão territorial, o estado se destaca no cenário nacional por sua localização estratégica e sua economia diversificada, que movimenta negócios das cadeias produtivas de petróleo e gás, siderurgia e mineração, celulose, rochas ornamentais, móveis, além de se destacar no agronegócio, com sua cafeicultura e fruticultura (GOVERNO DO ESTADO DO ESPÍRITO SANTO, 2017). 
A estrutura econômica capixaba passou por diversas mudanças ao longo do tempo para atingir este patamar. Inicialmente sua economia era considerada agrário-exportadora, focada na produção de café, e transformou-se em industrial entre os anos de 1960 a 1990. Após esse período, iniciou-se o $3^{\circ}$ Ciclo de Desenvolvimento Econômico, que se sabe, embora a economia capixaba tenha sido pouco estudada, que marcou a diversificação das atividades econômicas do estado (CAÇADOR e GRASSI, 2009).

Ainda segundo Caçador e Grassi (2009, p. 454), esse ciclo favoreceu o desenvolvimento de atividades econômicas importantes como "os serviços ligados ao comércio exterior, os setores de alimentos e bebidas, metal-mecânico, móveis, rochas ornamentais, vestuário, construção civil e serviços imobiliários", entre outros. Contudo, os autores afirmam que no estado houve pouco investimento de recursos na área de ciência e tecnologia, intensificando um processo chamado de “diversificação concentradora", em que, apesar da ampliação do leque de atividades desenvolvidas, houve concentração setorial na produção de commodities.

Como resultado desse novo modelo de desenvolvimento, o estado obteve crescimento na economia, que se diversificou e se integrou de forma consolidada ao restante do país. Hoje o Espírito Santo pode ser considerado uma das economias que mais crescem no Brasil, além de possuir a economia mais internacionalizada, se comparada com os demais estados (ROCHA e MORANDI, 2012).

De acordo com Francisco (2017), o PIB estadual é composto 56,3\% pelo setor de serviços, $34,5 \%$ pela indústria e 9,3\% pela agropecuária. Dentre as diversas atividades que garantem esta economia diversificada, o IBGE destaca os três grandes setores da economia capixaba. A Figura 5 apresenta a participação de cada uma no valor adicionado total, no período de 2002 a 2012.

No período analisado na Figura 5, o setor de serviços se destaca entre os demais, apresentando maior participação, seguido do setor industrial, que atingiu máxima participação de 39,2\% em 2012 e, por fim, a agropecuária, que não alcançou $10 \%$ de participação no período.

Segundo o IBGE (2004), o setor agropecuário é constituído pelas atividades de lavouras permanentes e temporárias, pecuária, silvicultura, horticultura, extrativa vegetal, investimentos para a 
formação de matas plantadas, pesca, indústria rural, produção particular e serviços auxiliares da agropecuária.

Figura 5 - Participação da agropecuária, indústria e serviços no valor adicionado total (em \%) Espírito Santo - 2002 a 2012

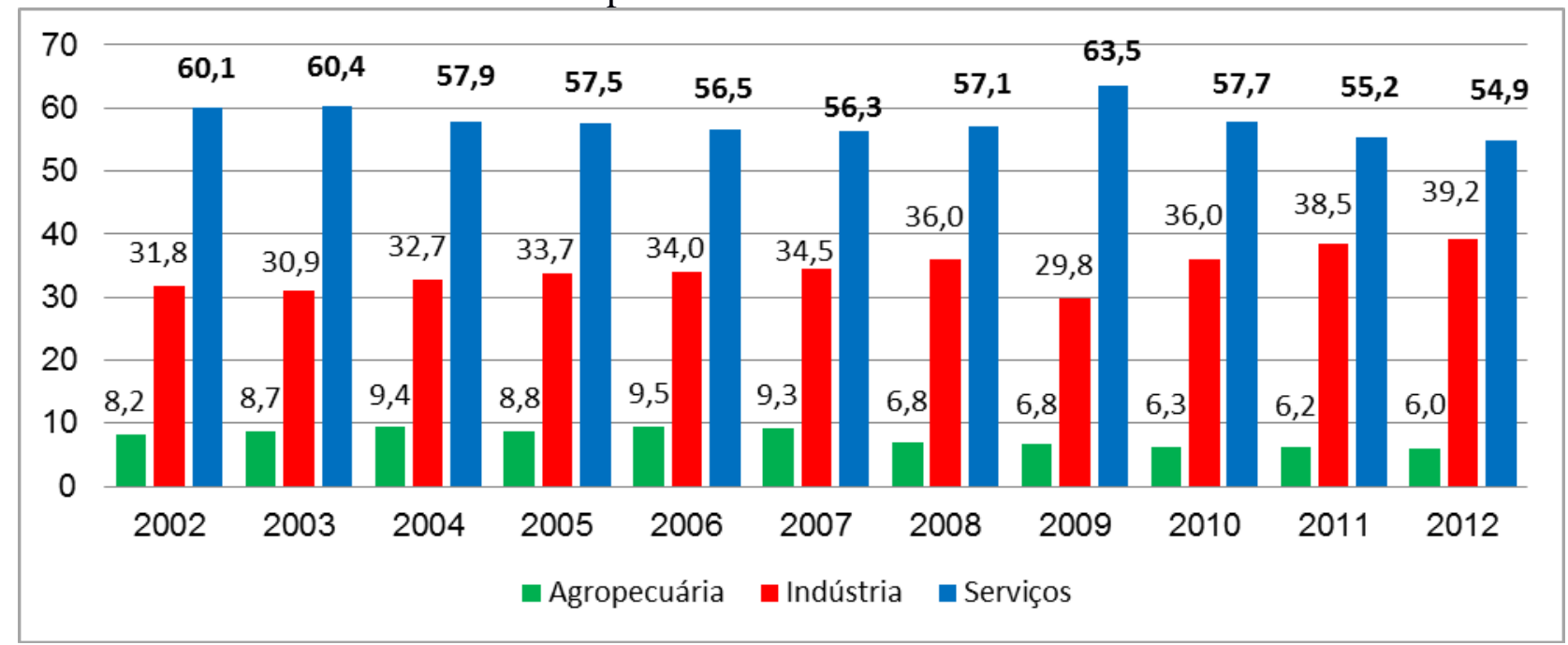

Fonte: IBGE (2017a)

No Espírito Santo, o setor agropecuário ainda é um dos principais geradores de fonte de renda e emprego para a maioria dos municípios (INCAPER, 2017). Ainda segundo o INCAPER (2017), as atividades como a cafeicultura, a fruticultura, a olericultura, o cultivo de cana-de-açúcar, de alimentos básicos e de especiarias são as principais atividades agrícolas no estado. Entre as atividades de produção animal, destacam-se a bovinocultura, avicultura, suinocultura, aquicultura e pesca. Já nas atividades extrativas, destacam-se aquelas de extração vegetal e silvicultura.

Dentre todas essas atividades, a cafeicultura é considerada a de maior importância no setor no Espírito Santo. O estado é destaque nacional na produção e exportação de café, sendo o grão responsável por aproximadamente 37,3\% do valor bruto da produção agropecuária capixaba em 2015, além de, no mesmo ano, representar 34,4\% das exportações do agronegócio capixaba (INCAPER, 2017). 
No que se refere ao setor industrial, o IBGE (2004) afirma que esse é representado pelas atividades extrativa mineral, construção civil, indústria de transformação e serviços industriais de utilidade pública.

Segundo Rocha e Morandi (2012), o setor industrial capixaba começou a receber grandes investimentos a partir de 1974, como consequência da crise de preços enfrentada pela atividade de cafeicultura em meados dos anos 70. Tais investimentos foram fundamentais, uma vez que determinaram modificações substantivas na estrutura desse setor.

Pode-se afirmar, portanto, que o Espírito Santo se especializou na produção e exportação de commodities, como rochas ornamentais, minério de ferro, placas e bobinas de aço, celulose de eucalipto, pellets de minério de ferro e, nos últimos anos, petróleo e gás natural (ROCHA e MORANDI, 2012).

A Indústria capixaba passa por constantes investimentos. A Figura 6 a seguir apresenta os investimentos previstos até o ano de 2017 e as principais atividades beneficiadas. Todas as atividades com maiores investimentos pertencem ao setor industrial.

Figura 6 - Investimentos anunciados segundo principais atividades (em \%) - Espírito Santo - 2012 a 2017

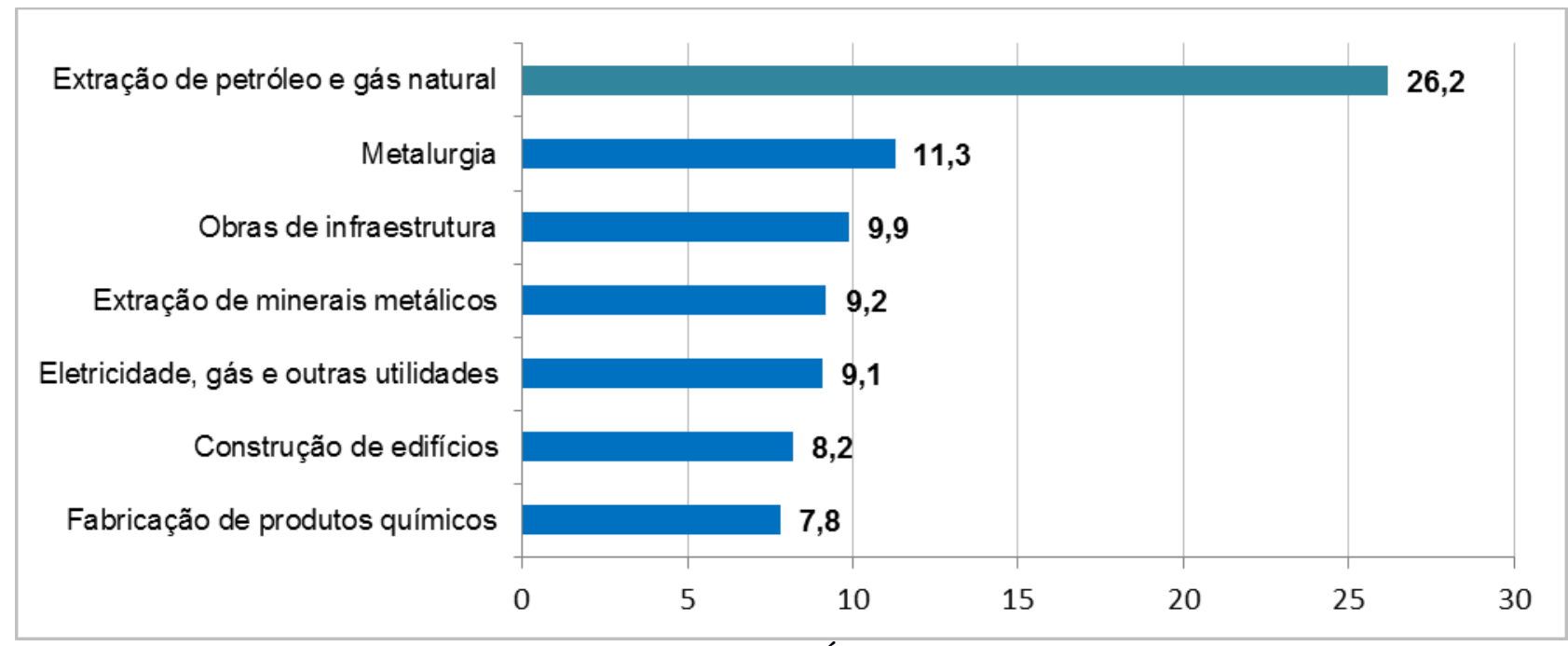

Fonte: PLANO DE DESENVOLVIMENTO DO ESPÍRITO SANTO (2013) 
A Figura 6 mostra que a atividade com maior previsão de investimentos é a extração de petróleo e gás natural. Isso se dá pelo fato de o estado ocupar a segunda posição nacional quando se trata de produção de petróleo e gás natural, representando cerca de 15\% da produção nacional (PLANO DE DESENVOLVIMENTO DO ESPÍRITO SANTO, 2013).

Por fim, o setor de serviços é formado por comércio, alojamento e alimentação, transportes, comunicações, serviços financeiros, atividades imobiliárias e serviços prestados às empresas, administração pública e demais serviços (IBGE, 2004).

No Espírito Santo, o setor de serviços só começou a apresentar maior relevância na economia a partir da década de 1960, pois a economia estadual era até então predominantemente agrícola, voltada para a produção de café (ROCHA e MORANDI, 2012).

Ainda de acordo com Rocha e Morandi (2012), o setor de serviços sofreu forte ampliação e diversificação no decorrer dos anos, como consequência da expansão do mercado urbano e do crescimento da demanda criada para o comércio, serviços pessoais, serviços públicos, atividades financeiras, entre outros.

Atualmente, o setor de serviços é o que mais se destaca na economia do estado, principalmente na Região Metropolitana da Grande Vitória. Este setor é responsável por 75\% dos empregos na capital capixaba (RODRIGUES, 2014).

O IBGE apresenta o percentual de participação das atividades do setor de serviços ao longo dos anos. Essa informação está representada na Figura 7.

A partir da análise da Figura 7, pode-se observar que o comércio teve um crescimento considerável ao longo de 10 anos, diante das quedas observadas nas outras atividades. Administração, saúde e educação públicas e seguridade social são outras atividades representativas. Essas, apesar de sofrerem quedas ao longo dos anos, possuem maior participação no valor adicionado do setor.

Entre as atividades do setor de serviços, o comércio exterior é a de maior destaque na economia capixaba. Ao se analisar o contexto histórico, pode-se observar o alto desempenho do comércio exterior estadual, que chegou a superar o nacional durante a década de 1990 (CAÇADOR e GRASSI, 2009). 
Figura 7 - Participação das atividades no valor adicionado do setor de serviços (em \%) - Espírito Santo

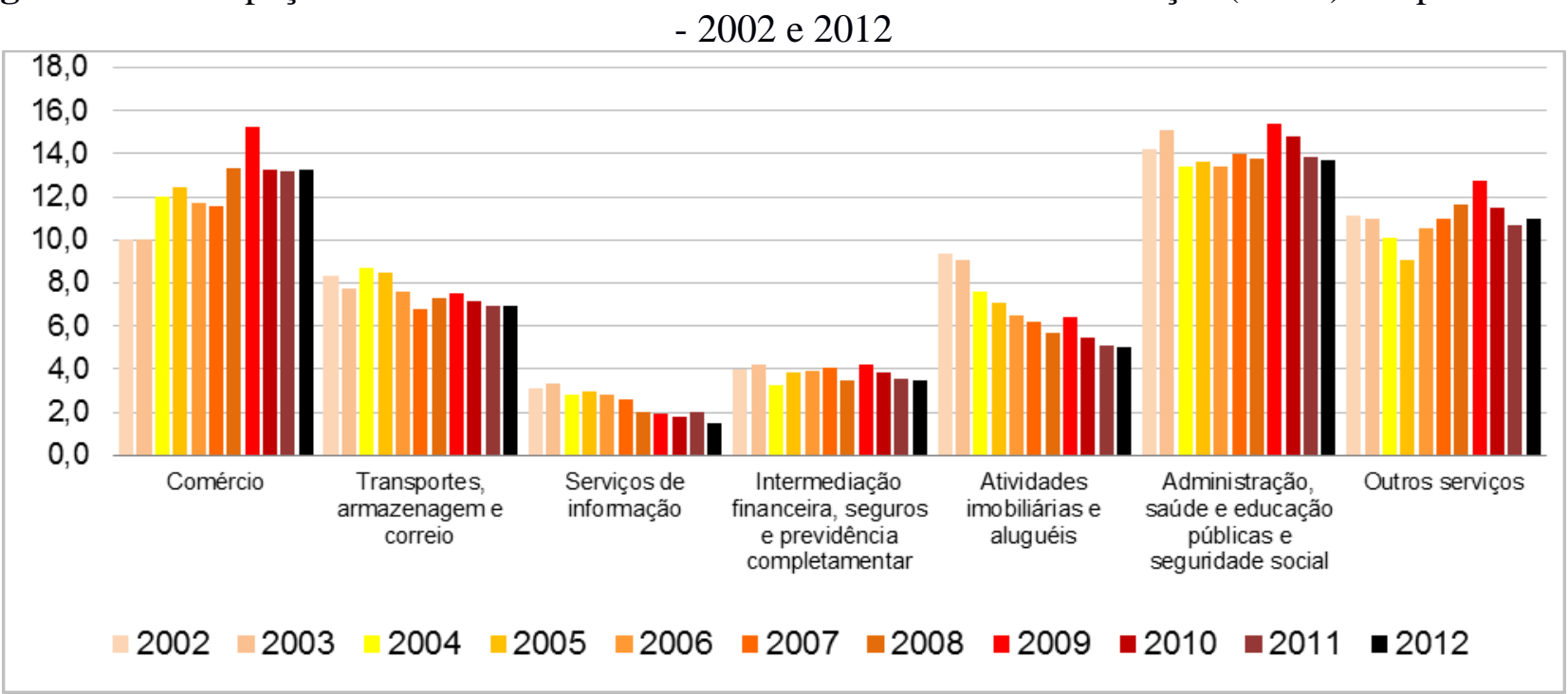

Fonte: IBGE (2017a)

De acordo com dados do Instituto Jones dos Santos Neves - IJSN (2017), atualmente a participação do Espírito Santo no comércio internacional brasileiro é de 3,6\% (importações e exportações). Essa contribuição vem, principalmente, dos números expressivos no comércio de minério e de café, além de outras commodities. A Figura 8 a seguir mostra o desempenho do comércio exterior nos últimos 4 anos.

De acordo com o IJSN (2017), o comércio exterior no estado apresentou um pequeno crescimento no ano de 2016, após tendência de queda iniciada a partir do terceiro trimestre de 2015. As exportações chegaram, no quarto trimestre de 2016, a US\$1,8 bilhão e as importações a US\$ 1,0 bilhão, gerando uma corrente de comércio de US\$2,7 bilhões.

O Espírito Santo pode ser caracterizado como um dos estados com maior grau de abertura do país, sendo considerado um estado exportador de bens básicos/ intermediários e importador de bens manufaturados (MAGALHÃES e TOSCANO, 2012).

Um dos fatores que favorecem o bom desempenho capixaba no segmento de comércio exterior é sua ampla e moderna infraestrutura portuária. No Espírito Santo estão situados um grande número de portos privados, voltados a atender às grandes empresas produtoras de commodities que ali atuam, 
como Vale, ArcelorMittal Tubarão, Samarco, Fibria e Petrobras, por exemplo (CAÇADOR e GRASSI, 2009).

Figura 8 - Exportações, Importações, Saldo Comercial e Corrente de Comércio (em US\$ bilhões) Espírito Santo - Resultado trimestral de 2012 a 2016

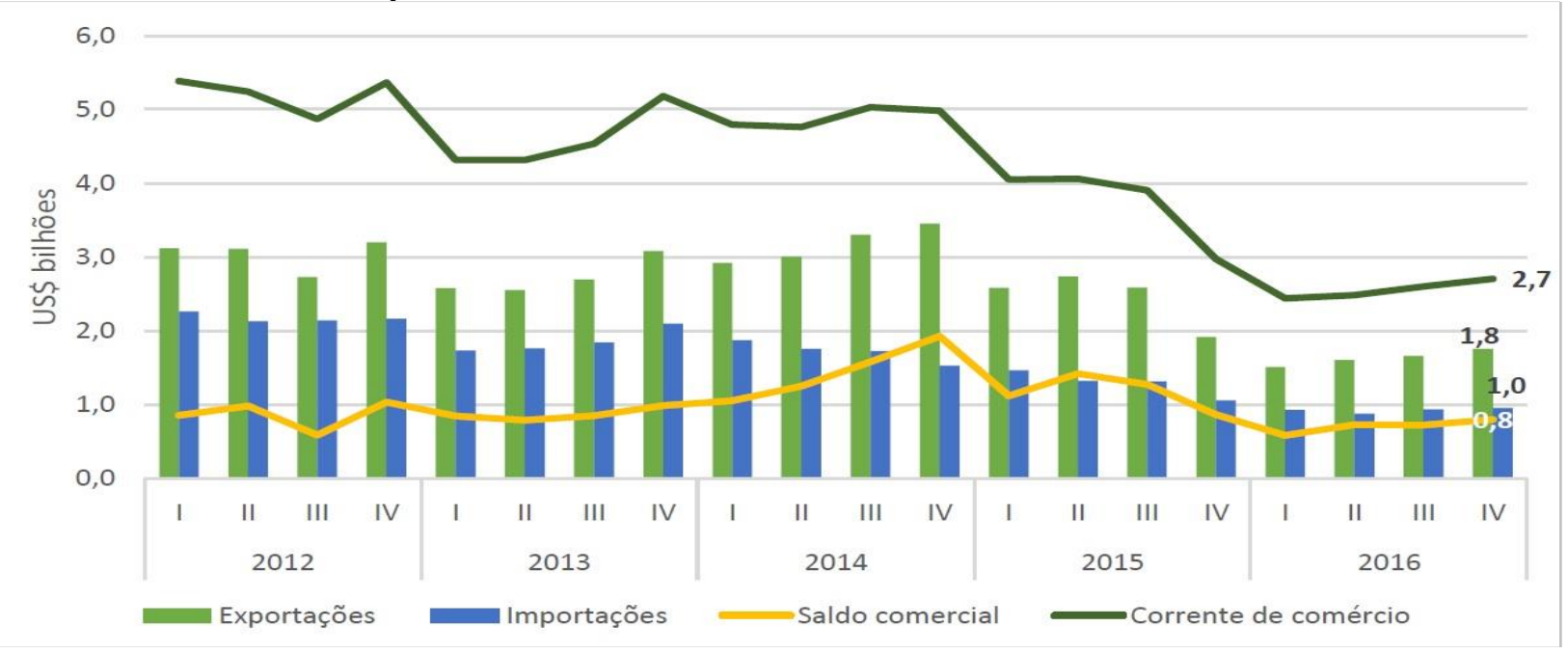

Fonte: IJSN (2017)

\section{PROCEDIMENTOS METODOLÓGICOS}

Segundo Gil (2010), é importante classificar as pesquisas, pois isso permite reconhecer diferenças e semelhanças entre as modalidades existentes. Assim, o pesquisador passa a ter mais elementos para decidir sobre a aplicabilidade do estudo na solução dos problemas da investigação.

Desta forma, adotou-se a classificação segundo Fonseca (2002), que propõe a adoção de três critérios: quanto à abordagem, quanto ao objetivo e quanto aos procedimentos.

Quanto à abordagem, esta pesquisa pode ser classificada como quantitativa, pois "se centra na objetividade, influenciada pelo positivismo, considera que a realidade só pode ser compreendida com base na análise de dados brutos, recolhidos com o auxílio de instrumentos padronizados e neutros" (FONSECA, 2002, p. 20).

Quanto ao objetivo, pode ser classificada como descritiva, pois pretende descrever os fatos e fenômenos de determinada realidade (TRIVIÑOS, 1987; FONSECA, 2002). 
Por fim, quanto aos procedimentos, pode ser definida como pesquisa de levantamento, pois, para Fonseca (2002), esse tipo de pesquisa aplica-se a estudos exploratórios e descritivos, em que o levantamento de informações pode ser obtido através de uma amostra ou censo.

Para a construção da base teórica, foram pesquisados periódicos que abordam o tema em questão, serviços. Após leitura dos materiais encontrados, foram selecionados os que mais contribuíam para o presente estudo.

A fim de se alcançar o objetivo deste trabalho, descrito anteriormente, utilizou-se os dados da Pesquisa Mensal de Serviços (PMS) realizada pelo Instituto Brasileiro de Geografia e Estatística IBGE, que tem seus resultados disponibilizados no site da instituição.

A Pesquisa Mensal de Serviços (PMS) produz indicadores que auxiliam no acompanhamento do comportamento conjuntural do setor de serviços no Brasil e nos estados, investigando a receita bruta de serviços nas empresas formalmente constituídas, com 20 ou mais pessoas ocupadas, que desempenham como principal atividade um serviço não financeiro, excluídas as áreas de saúde e educação (IBGE, 2017b).

A pesquisa é composta por indicadores gerais para o Brasil e para as 27 Unidades da Federação, abrangendo as atividades de acordo com os seguintes grupos e subgrupos: serviços prestados às famílias; serviços de informação e comunicação; serviços profissionais, administrativos e complementares; transportes, serviços auxiliares aos transportes e correio; e outros serviços.

A metodologia utilizada pelo IBGE para a realização da PMS pode ser estruturada, de forma resumida, da seguinte maneira:

- Âmbito: é definido pelo universo das empresas que: possuam 20 ou mais pessoas ocupadas, cuja receita provenha, predominantemente, da atividade de prestação de serviços; estejam em situação ativa no Cadastro Central de Empresas - Cempre, do IBGE; estejam sediadas no território nacional; tenham atividade principal compreendida nos cinco grupos de atividades da Classificação Nacional de Atividades Econômicas - CNAE 2.0; 
- Unidade de investigação: a unidade básica de informação da PMS é a empresa, definida como entidade jurídica caracterizada por firma ou razão social, inscrita no Cadastro Nacional de Pessoa Jurídica (CNPJ);

- Variável investigada: é a receita bruta de serviços, total e por Unidade da Federação, definida como a receita proveniente das atividades de prestação de serviços, sem dedução de impostos e contribuições incidentes, abatimentos e descontos incondicionais. Não estão incluídas as receitas financeiras e não operacionais;

- Amostra: A PMS tem como base amostral o estrato certo da Pesquisa Anual de Serviços 2008, formado por cerca de 46.000 empresas com 20 ou mais pessoas ocupadas, buscando garantir representatividade por Unidade da Federação e por atividade;

- Série de receita nominal e de volume: A PMS divulga, a partir da variável investigada, Índices de receita nominal e de volume, este último como resultado da deflação dos valores nominais correntes por índices de preços específicos para cada grupo de atividade, e para cada Unidade da Federação, construídos a partir dos relativos de preços do IPCA;

- Divulgação dos resultados: Os resultados da PMS e os comentários elaborados pela Coordenação de Serviços e Comércio são disponibilizados no periódico Indicadores do IBGE e no Sistema IBGE de Recuperação Automática - Sidra, no portal do IBGE na Internet, no endereço: 〈http:// www.ibge.gov.br>.

O período analisado nesta pesquisa é referente a janeiro de 2012 a maio de 2017. Esse período foi definido devido à disponibilidade, no site do IBGE, dos dados que serviram para elaboração dos gráficos, quadros e tabelas, não sendo possível buscar informações anteriores a janeiro de 2012.

Posteriormente verificou-se a possível relação entre a crise econômica e o baixo desempenho do setor de serviços no período analisado, através de sua comparação com as taxas de inflação no país 
(IPCA) e com o número de empregos formais no setor de serviços no estado no mesmo período. Por fim, foram relatados os principais impactos sobre o setor, bem como sobre a economia capixaba.

O primeiro parâmetro usado como comparativo foi o índice de inflação. A inflação indica o aumento persistente e generalizado dos preços. No Brasil, o índice oficial utilizado para medi-la é o IPCA - Índice de Preços ao Consumidor Ampliado. O IPCA mede a variação de preços do mercado para o consumidor final. Esse indicador é obtido pelo IBGE, através da medição do custo de vida das famílias com renda de 01 a 40 salários-mínimos em 9 regiões metropolitanas brasileiras. A pesquisa calcula despesas com vestuário, alimentação e bebidas, moradia, educação, transporte, comunicação, artigos para casa, despesas pessoais, saúde e higiene pessoal. Uma alta no IPCA significa que pelo menos uma dessas despesas sofreu reajuste de preço.

De forma geral, a alta taxa de inflação é prejudicial para a economia, uma vez que contribui para a desvalorização da moeda, além de influenciar na diminuição dos investimentos no setor produtivo, no aumento da especulação financeira, na alta do dólar, na elevação da taxa de juros e no aumento do desemprego. Isso, por consequência, agrava ainda mais uma economia que passa por um momento de recessão.

O outro indicador utilizado como comparativo foi o número de empregos formais gerados pelo setor de serviços no Espírito Santo. Esse indicador é obtido através de pesquisa realizada pelo Instituto Jones dos Santos Neves e divulgada mensalmente em sua resenha de conjuntura, que apresenta a evolução do emprego formal por setor de atividade econômica. O índice obtido na pesquisa é o saldo líquido, resultado da subtração entre admissões e demissões. Assim, um saldo positivo significa a criação de postos de trabalho com carteira assinada. Já um saldo negativo, significa que o número de demissões superou o número de admissões.

\section{RESULTADOS E DISCUSSÃO}

A fim de entender os impactos causados pela crise econômica sobre o setor de serviços no Espírito Santo, foram analisadas quatro fontes de dados. A primeira se refere à variação da receita nominal de serviços no Espírito Santo (Pesquisa Mensal de Serviços - Instituto Brasileiro de Geografia e Estatística). A segunda se refere à variação do volume de serviços no estado (Pesquisa Mensal de 
Serviços - IBGE Instituto Brasileiro de Geografia e Estatística). A terceira, ao número de empregos formais no setor de serviços no estado (Pesquisa Mensal de Emprego Formal - Instituto Jones dos Santos Neves). E a última, à taxa de inflação acumulada em nível nacional (Índice Nacional de Preços ao Consumidor Amplo - IBGE).

A partir da Pesquisa Mensal de Serviços (PMS) do IBGE, foram coletados os dados referentes ao percentual de variação da receita nominal de serviços no estado do Espírito Santo, para o período de janeiro de 2012 até maio de 2017, totalizando uma amostra com 65 dados, agrupados na Tabela 1 a seguir.

Tabela 1 - Variação da Receita Nominal de Serviços no Espírito Santo (em \%) - janeiro de 2012 a

\begin{tabular}{l|c|cccccc}
\multicolumn{1}{c}{ Mês } & $\mathbf{2 0 1 2}$ & $\mathbf{2 0 1 3}$ & $\mathbf{2 0 1 4}$ & $\mathbf{2 0 1 5}$ & $\mathbf{2 0 1 6}$ & $\mathbf{2 0 1 7}$ \\
\hline Janeiro & 17,9 & 2,1 & 5,0 & 4,3 & $-8,3$ & 11,2 \\
\hline Fevereiro & 16,0 & 3,8 & 6,4 & $-2,5$ & 4,0 & $-4,5$ \\
\hline Março & 12,3 & 4,2 & 2,9 & 4,5 & $-6,0$ & 5,4 \\
\hline Abril & 8,7 & 11,2 & 2,3 & $-4,8$ & $-5,0$ & 3,1 \\
\hline Maio & 11,5 & 6,5 & 0,4 & $-4,1$ & $-2,8$ & 6.6 \\
\hline Junho & 8,2 & 5,1 & $-3,2$ & 3,8 & $-4,8$ & - \\
\hline Julho & 8,5 & 12,0 & $-6,4$ & $-2,9$ & $-3,3$ & - \\
\hline Agosto & 5,2 & 6,6 & $-0,6$ & 4,2 & $-9,1$ & - \\
\hline Setembro & 3,5 & 7,9 & 6,2 & $-3,3$ & $-6,0$ & - \\
\hline Outubro & 7,7 & 5,6 & 4,6 & $-5,8$ & $-5,4$ & - \\
\hline Novembro & 5,2 & 4,7 & 5,3 & $-4,4$ & $-6,7$ & - \\
\hline Dezembro & 1,0 & 3.3 & 7,6 & $-4,7$ & $-2,5$ & - \\
\hline
\end{tabular}

Fonte: Elaborada pelos autores a partir dos dados da Pesquisa Mensal de Serviços do IBGE

A variação da receita nominal representa o desempenho do setor de serviços em comparação com igual mês do ano anterior. Através da Tabela 1 pode-se notar que a variação da receita nominal se apresenta positiva de janeiro de 2012 até maio de 2014. A partir daí, a variação torna-se negativa nos meses de junho, julho e agosto, retornando a valores positivos nos meses de setembro de 2014 a janeiro de 2015.

Em fevereiro de 2015, a variação se apresenta novamente negativa em todos os meses, estendendo-se até o mês de dezembro de 2016 (com exceção de março, junho e agosto de 2015, e fevereiro de 2016). Já em 2017, o ano iniciou com uma variação de 11,2\%, apresentando queda em fevereiro, porém com retomada nos meses subsequentes. 
Os dados da Tabela 1 ficam ainda mais evidentes ao se plotar o gráfico, conforme mostra a Figura 9, representando a variação ao longo do tempo analisado.

Figura 9 - Variação da Receita Nominal de Serviços no Espírito Santo (em \%) - janeiro de 2012 a maio de 2017

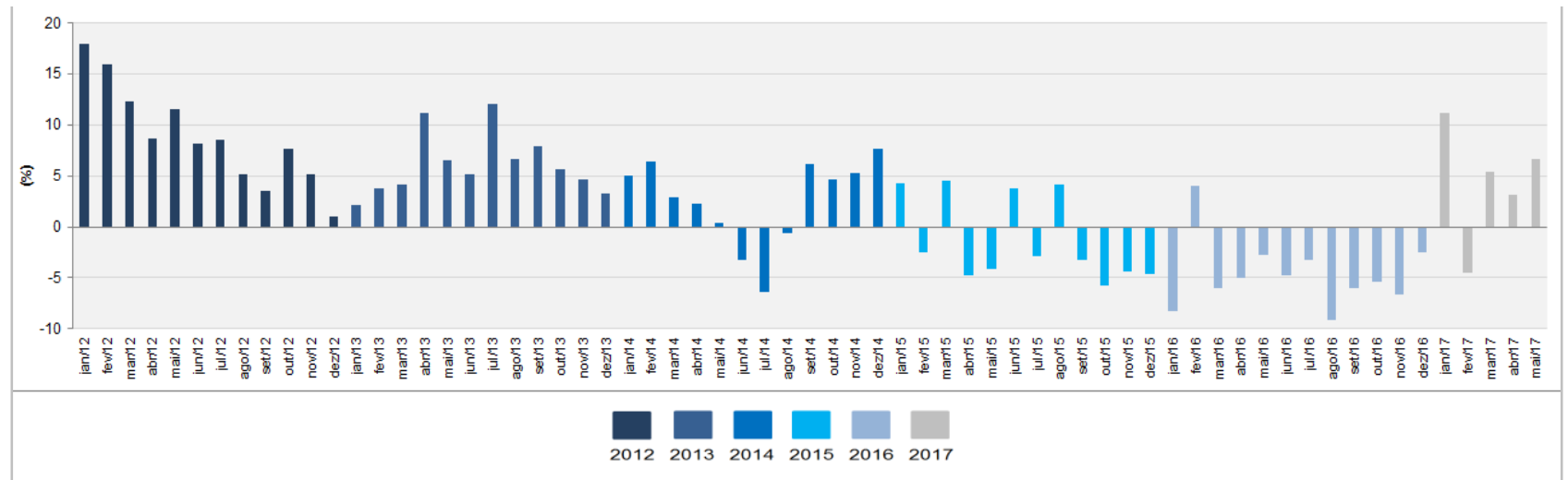

Fonte: Elaborada pelos autores a partir dos dados da Pesquisa Mensal de Serviços do IBGE

É notável a variação negativa, que se estende pela maior parte do período analisado, com maior impacto a partir de 2015, quando a crise econômica brasileira mostrava seus primeiros indícios. Começa-se aí a se verificar diretamente alguns impactos da crise sobre o setor de serviços.

Outro indicador analisado neste estudo foi a variação do volume de serviços. O índice também foi obtido a partir da PMS, onde foram coletados os dados referentes à variação da receita nominal de serviços no estado do Espírito Santo em comparação com igual mês do ano anterior. Novamente, o período analisado foi de janeiro de 2012 a maio de 2017. Os dados coletados foram agrupados conforme mostra a Tabela 2 a seguir.

Conforme é mostrado na Tabela 2 acima, a variação do volume de serviços no estado do Espírito Santo se mostrou positiva na maioria dos meses dos anos de 2012 e 2013, apresentando variações negativas em apenas cinco dos vinte e quatro meses, mas que não chegam a ser menores que $-4,1 \%$.

Já a partir de 2014, a variação do volume de serviços foi negativa entre os meses de março a agosto. Nos dois anos seguintes, as variações negativas se estenderam por todos os meses, com exceção de junho de 2015, em que atingiu um valor pouco expressivo, de 0,3\%. 
Nos anos de 2015 e de 2016, que apresentaram as menores variações de volume, o pior indicador registrado foi em agosto de 2016, alcançando -13,9\%. A partir de setembro de 2016 as variações ainda permanecem negativas, porém convergem para resultados um pouco menos negativos, alcançando $-4,9 \%$ em dezembro.

Tabela 2 - Variação do Volume de Serviços no Espírito Santo (em \%) - janeiro de 2012 a maio de

\begin{tabular}{l|c|c|c|c|c|c}
\multicolumn{1}{c}{ Mês } & $\mathbf{2 0 1 2}$ & $\mathbf{2 0 1 3}$ & $\mathbf{2 0 1 4}$ & $\mathbf{2 0 1 5}$ & $\mathbf{2 0 1 6}$ & $\mathbf{2 0 1 7}$ \\
\hline Janeiro & 8,4 & $-1,0$ & 1,3 & $-3,5$ & $-11,2$ & 4,5 \\
\hline Fevereiro & 6,7 & 0,4 & 2,2 & $-8,4$ & $-0,7$ & $-9,9$ \\
\hline Março & 5,1 & 1,6 & $-2,6$ & $-0,2$ & $-9,3$ & $-2,0$ \\
\hline Abril & 1,0 & 9,3 & $-3,7$ & $-9,5$ & $-7,6$ & $-3,1$ \\
\hline Maio & 4,8 & 3,7 & $-4,9$ & $-8,0$ & $-5,9$ & 0,3 \\
\hline Junho & 2,4 & 1,0 & $-8,7$ & 0,3 & $-7,4$ & - \\
\hline Julho & 1,0 & 9,8 & $-10,3$ & $-7,6$ & $-6,8$ & - \\
\hline Agosto & $-0,7$ & 2,1 & $-4,8$ & $-0,3$ & $-13,9$ & - \\
\hline Setembro & $-1,8$ & 4,1 & 1,2 & $-6,8$ & $-10,1$ & - \\
\hline Outubro & 3,2 & 1,1 & 0,0 & $-10,0$ & $-8,6$ & - \\
\hline Novembro & 0,6 & 0,1 & 1,3 & $-9,2$ & $-9,3$ & - \\
\hline Dezembro & $-4,1$ & $-1,1$ & 2,5 & $-8,9$ & $-4,9$ & - \\
\hline
\end{tabular}

Fonte: Elaborada pelos autores a partir dos dados da Pesquisa Mensal de Serviços do IBGE

Em 2017 é atingida uma variação positiva em janeiro, que logo é sequenciada por duas variações negativas, em fevereiro e março. Por fim, a análise termina no mês de maio, que apresenta variação positiva, porém não tão expressiva $(0,3 \%)$.

A Figura 10 a seguir apresenta a variação do volume de serviços no estado do Espírito Santo, mostrando claramente o péssimo desempenho do setor de serviços durante o período analisado.

Apesar de ser bastante nítido o desempenho negativo do setor no período analisado, buscou-se estabelecer um comparativo com algum indicador que servisse de parâmetro de análise da crise. Como primeiro parâmetro de comparação, adotaram-se as taxas de inflação no país durante o mesmo período.

A fonte de dados para obtenção das taxas no período foi o Índice Nacional de Preços ao Consumidor Amplo, IPCA. Este é calculado pelo IBGE desde 1980 e se refere às famílias com rendimento monetário de 01 a 40 salários-mínimos, qualquer que seja a fonte. Neste estudo as taxas de 
inflação apresentadas referem-se às taxas acumuladas de doze meses. Essas variações podem ser visualizadas através da Tabela 3 a seguir.

Figura 10 - Variação da Receita Nominal de Serviços no Espírito Santo (em \%) - janeiro de 2012 a maio de 2017

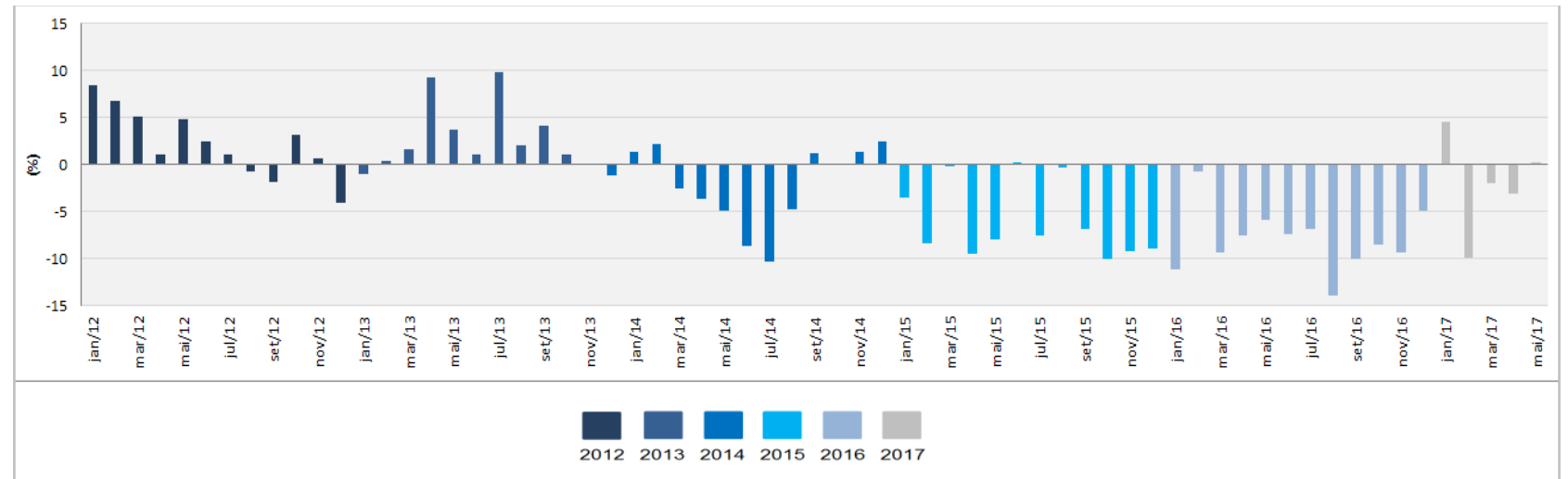

Fonte: Elaborada pelos autores a partir dos dados da Pesquisa Mensal de Serviços do IBGE

Tabela 3 - Taxa de inflação no Brasil (em \%) - janeiro de 2012 a maio de 2017

\begin{tabular}{l|c|c|c|c|c|c}
\hline \multicolumn{1}{c}{ Mês } & $\mathbf{2 0 1 2}$ & $\mathbf{2 0 1 3}$ & $\mathbf{2 0 1 4}$ & $\mathbf{2 0 1 5}$ & $\mathbf{2 0 1 6}$ & $\mathbf{2 0 1 7}$ \\
\hline Janeiro & 6,22 & 6,15 & 5,59 & 7,14 & 10,71 & 5,35 \\
\hline Fevereiro & 5,85 & 6,31 & 5,68 & 7,70 & 10,36 & 4,76 \\
\hline Março & 5,24 & 6,59 & 6,15 & 8,13 & 9,39 & 4,57 \\
\hline Abril & 5,10 & 6,49 & 6,28 & 8,17 & 9,28 & 4,08 \\
\hline Maio & 4,99 & 6,50 & 6,38 & 8,49 & 9,32 & 3,60 \\
\hline Junho & 4,92 & 6,70 & 6,52 & 8,89 & 8,84 & - \\
\hline Julho & 5,20 & 6,27 & 6,50 & 9,56 & 8,74 & - \\
\hline Agosto & 5,24 & 6,09 & 6,51 & 9,53 & 8,97 & - \\
\hline Setembro & 5,28 & 5,86 & 6,75 & 9,49 & 8,48 & - \\
\hline Outubro & 5,45 & 5,84 & 6,59 & 9,93 & 7,87 & - \\
\hline Novembro & 5,53 & 5,77 & 6,56 & 10,48 & 6,99 & - \\
\hline Dezembro & 5,84 & 5,91 & 6,41 & 10,67 & 6,29 & - \\
\hline
\end{tabular}

Fonte: Elaborada pelos autores a partir do Índice Nacional de Preços ao Consumidor Amplo do IBGE

Ao se analisar os dados referentes às taxas de inflação no período, pode-se observar que essa começou a ser superior a 7\% a partir de janeiro de 2015, estendendo-se assim por todo o ano, cuja meta estipulada pelo Banco Central era de 9,5\%. Em dezembro de 2015, porém, o indicador chegou a atingir $10,67 \%$.

Somente a partir de março de 2016, pode-se observar queda moderada do indicador no decorrer 
dos meses, alcançando, em dezembro daquele ano, uma taxa de 6,29\%. Já nos primeiros meses de 2017 a inflação deu sinais de queda, atingindo patamares mais baixos, até mesmo quando comparados aos períodos anteriores. Em maio de 2017 o indicador atingiu 4,08\%, a menor taxa em todo o período analisado. A variação da taxa de inflação ao longo do período analisado encontra-se na Figura 11 a seguir, onde fica fácil a sua visualização.

Figura 11 - Variação da Taxa de Inflação no Brasil (em \%) - janeiro de 2012 a maio de 2017

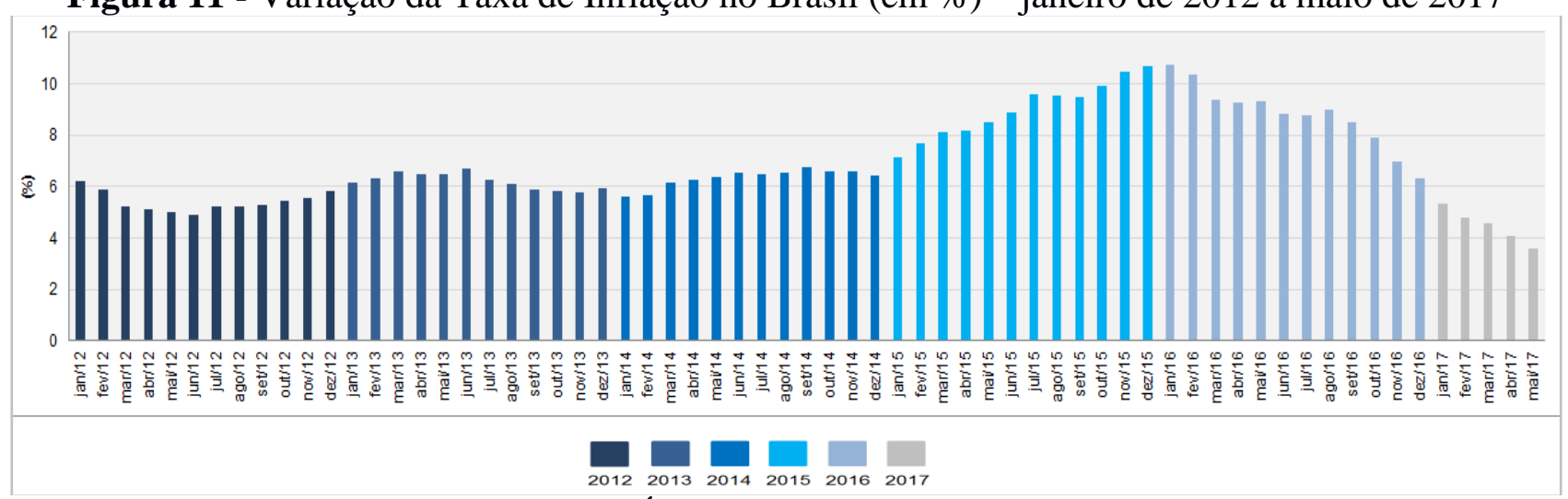

Fonte: Elaborada pelos autores a partir do Índice Nacional de Preços ao Consumidor Amplo do IBGE

Para se estabelecer o segundo parâmetro de comparação, levou-se em consideração o saldo líquido de empregos formais, indicador divulgado mensalmente pelo Instituto Jones dos Santos Neves e que pode ter seus resultados conferidos na Tabela 4 que segue.

Tabela 4 - Emprego formal no setor de serviços no Espírito Santo (Saldo líquido = admissões demissões) - janeiro de 2012 a maio de 2017

\begin{tabular}{lccccccc}
\hline \multicolumn{1}{c}{ Mês } & $\mathbf{2 0 1 2}$ & $\mathbf{2 0 1 3}$ & $\mathbf{2 0 1 4}$ & $\mathbf{2 0 1 5}$ & $\mathbf{2 0 1 6}$ & $\mathbf{2 0 1 7}$ \\
\hline Janeiro & 1.045 & 531 & -865 & -202 & -1.100 & 432 \\
\hline Fevereiro & 1.844 & 1.100 & 2.699 & 409 & -934 & 449 \\
\hline Março & 1.069 & 2.461 & 841 & -1.028 & -1.462 & -329 \\
\hline Abril & 2.071 & 800 & 1.334 & -2.347 & -794 & 561 \\
\hline Maio & 577 & 500 & 611 & -1.603 & -1.380 & 18 \\
\hline Junho & -332 & 439 & -16 & -1.426 & -1.147 & - \\
\hline Julho & 893 & -704 & 756 & -543 & -831 & - \\
\hline Agosto & 483 & 1.277 & 1.542 & -698 & -1.043 & - \\
\hline Setembro & 1.084 & 691 & 1.587 & -1.946 & -641 & - \\
\hline Outubro & 842 & 391 & 307 & -1.512 & -1.015 & - \\
\hline Novembro & 504 & 440 & 544 & -965 & -1.079 & - \\
\hline Dezembro & -1.118 & -1.587 & -2.340 & -3.936 & -2.939 & - \\
\hline
\end{tabular}

Fonte: Elaborada pelos autores a partir dos dados das Resenhas de Conjuntura do IJSN 
A Tabela 4 acima mostra que nos anos entre 2012 e 2015 o número de admissões no setor de serviços foi superior ao número de demissões. Apesar de apresentar saldo negativo em alguns meses nesse período, pode-se afirmar que são pontuais e podem ser justificados como meses sazonais, uma vez que ocorrem nos meses de junho e dezembro. A partir de 2015, o saldo líquido de empregos formais torna-se negativo. Ou seja, o número de demissões do setor de serviços capixaba foi superior ao número de admissões. Apenas nesses dois anos, o número de demissões chegou a atingir 30.162 (número acumulado de saldo líquido nos anos de 2015 e 2016).

A partir de janeiro de 2017 o indicador dá sinais de melhora, constatado pelo saldo líquido positivo de 432, seguido por saldo positivo em fevereiro. No mês de março há novamente saldo negativo, com 329 demissões. Nos dois meses subsequentes há uma retomada, apesar de não tão expressiva.

Para melhor análise e visualização, foi plotado o gráfico do indicador, onde é possível verificar, de forma mais clara, a queda do número de empregos formais gerados pelo setor de serviços no Espírito Santo. O gráfico se encontra na Figura 12 a seguir.

Figura 12 - Emprego formal no setor de serviços no Espírito Santo (Saldo líquido = admissões demissões) - janeiro de 2012 a maio de 2017

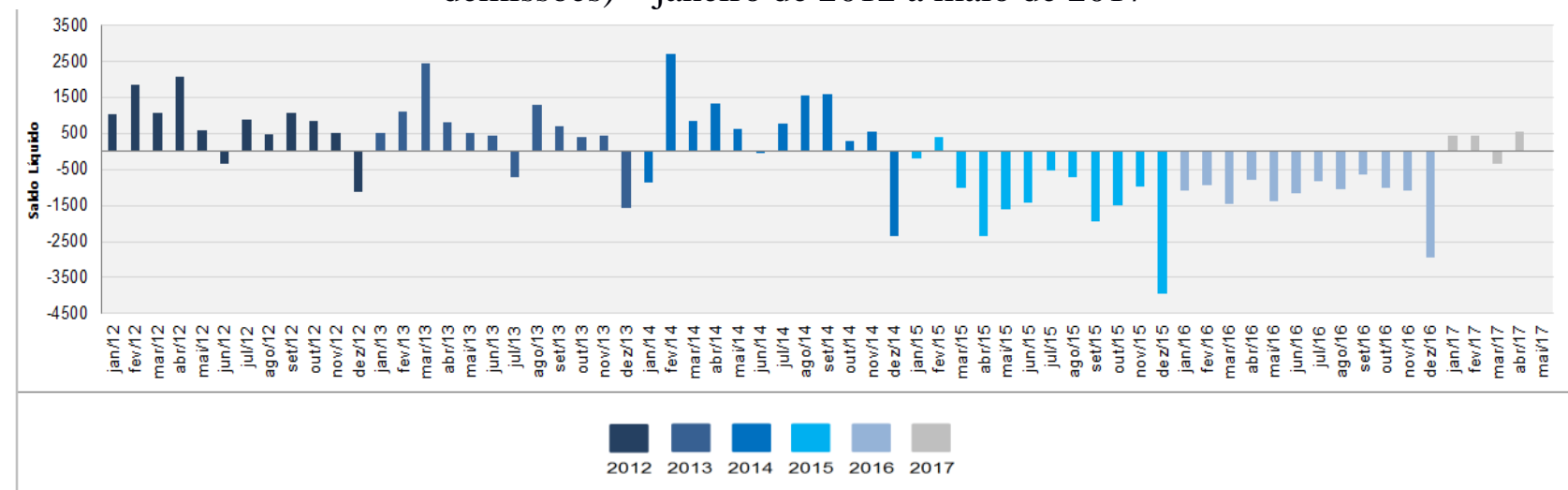

Fonte: Elaborada pelos autores a partir dos dados das Resenhas de Conjuntura do IJSN

Ao se comparar os quatro indicadores, observa-se que enquanto a receita nominal e a variação do volume de serviços apresentavam variações negativas, a taxa de inflação alcançou patamares altos. 
O mesmo pode ser observado em relação ao número de empregos formais gerados pelo setor, que apresentou um número de demissões superior ao número de admissões.

Desta maneira, pode-se estabelecer um quadro comparativo entre os indicadores apresentados. O Quadro 2 demonstra o desempenho de cada indicador, divididos os períodos de 2012 a 2014, 2015 e 2016 e, finalmente, 2017.

Quadro 2 - Comparativo entre os quatro indicadores

\begin{tabular}{|c|c|c|c|}
\hline INDICADOR & $\begin{array}{c}\text { JAN/2012 a } \\
\text { DEZ/2014 }\end{array}$ & $\begin{array}{l}\text { JAN/2015 a } \\
\text { DEZ/ } 2016\end{array}$ & $\begin{array}{c}\text { JAN/2017 a } \\
\text { MAI/2017 }\end{array}$ \\
\hline $\begin{array}{l}\text { Variação da receita nominal de } \\
\text { serviços }\end{array}$ & $\begin{array}{l}\text { Maior parte das } \\
\text { variações da receita foi } \\
\text { positiva. }\end{array}$ & $\begin{array}{l}\text { Maior parte das } \\
\text { variações da receita } \\
\text { foi negativa. } \\
\end{array}$ & $\begin{array}{c}\text { Retomada das } \\
\text { variações da receita } \\
\text { positivas. } \\
\end{array}$ \\
\hline Variação do volume de serviços & $\begin{array}{l}\text { Maior parte das } \\
\text { variações do volume de } \\
\text { serviço foi positiva. }\end{array}$ & $\begin{array}{l}\text { Praticamente todas as } \\
\text { variações do volume } \\
\text { de serviços no período } \\
\text { foram negativas. }\end{array}$ & $\begin{array}{l}\text { Variação do volume } \\
\text { de serviços ainda } \\
\text { permanece negativa na } \\
\text { maioria dos meses, } \\
\text { mas com tendência de } \\
\text { retomada no mês de } \\
\text { maio. }\end{array}$ \\
\hline Índice de inflação acumulada & $\begin{array}{c}\text { Taxa de inflação estável, } \\
\text { com maior índice em } \\
\text { setembro de } 2014 \\
(6,75 \%) .\end{array}$ & $\begin{array}{c}\text { Taxa de inflação alta, } \\
\text { atingindo maior índice } \\
\text { em janeiro de } 2016 \\
(10,71 \%) .\end{array}$ & $\begin{array}{c}\text { Queda na taxa de } \\
\text { inflação, atingindo } \\
\text { menor índice dos } \\
\text { últimos anos em maio } \\
(3,60 \%) .\end{array}$ \\
\hline $\begin{array}{l}\text { Emprego formal no setor de } \\
\text { serviços (Saldo líquido) }\end{array}$ & $\begin{array}{l}\text { Saldo líquido de } 22.301 \\
\text { empregos formais. }\end{array}$ & $\begin{array}{l}\text { Saldo líquido de - } \\
30.162 \text { empregos } \\
\text { formais. }\end{array}$ & $\begin{array}{l}\text { Saldo líquido de } 1.131 \\
\text { empregos formais. }\end{array}$ \\
\hline
\end{tabular}

Fonte: Elaborado pelos autores

No Quadro 2 fica nítido o péssimo desempenho dos indicadores nos anos de 2015 e 2016, coincidindo com o os primeiros efeitos da crise econômica e política sofrida no país. No mesmo período, a recessão é agravada, ainda mais, pela alta taxa de inflação.

Vale ressaltar que não foi analisada especificamente a crise, mas sim o "efeito dominó" que afetou o setor de serviços no Espírito Santo.

O estudo evidenciou os impactos sobre a receita e sobre o volume de serviços, resultando na diminuição de postos formais de trabalho no setor de serviços do estado. Apesar de tudo, os primeiros 
meses de 2017 dão sinais, mesmo que retraídos, de que há uma perspectiva de melhora para os indicadores. O setor volta a gerar empregos, em consequência da receita e do volume de serviços que voltam a apresentar crescimento. Em contramão, as taxas de inflação começam a cair, atingindo um patamar de 3,60\%, um dos menores nos últimos anos.

Pelo fato do setor de serviços representar a maior fatia do PIB estadual, o Espírito Santo foi gravemente afetado pela crise vivida no país. Uma vez que o setor de serviços não apresente um bom desempenho, isso acaba acarretando em menor consumo e menor produção, impactando diretamente na economia do estado.

\section{CONSIDERAÇÕES FINAIS}

A crise econômica e política em que o Brasil se encontra desde 2015 vêm mostrando a característica oscilatória da economia brasileira. O aumento das taxas de inflação, resultando na diminuição do poder de consumo da população devido ao aumento dos preços dos produtos e serviços, é uma característica marcante da recessão. Além desses fatores, a queda dos preços de ações e a diminuição de investimentos públicos e privados no Brasil, pela incerteza e instabilidade tanto econômica como política em que o país se encontra, acabam por contribuir para as altas taxas de desemprego.

Os reflexos disso puderam ser constatados através dos péssimos indicadores apresentados pelo Brasil em 2015: PIB negativo (-3,6\%), taxa de desemprego de 8,5\%, e alta taxa de inflação, que atingiu $10,7 \%$.

Não obstante o cenário nacional, o Espírito Santo teve sua economia fortemente afetada, em especial no que se refere ao setor de serviços. Estudos apresentados no referencial teórico mostram que a maior parte do PIB estadual é composta pelo setor de serviços e que esse se constitui como um dos que mais empregam no estado.

Diante do objetivo desta pesquisa, pôde ser observada uma forte evidência da relação entre o período de crise econômica e os impactos desta sobre o setor de serviços no estado Espírito Santo. Os indicadores fornecidos pela Pesquisa Mensal de Serviços (variação de receita nominal e variação do 
volume de serviços) mostraram que nos meses compreendidos entre 2015 e 2016, coincidentes com os primeiros sinais da crise, o desempenho do setor foi um dos piores.

Como principal impacto da crise sobre o setor, está o saldo líquido negativo do emprego formal no setor de serviços capixaba. Ou seja, o número de demissões superou o número de contratações. No período compreendido entre janeiro de 2015 e dezembro de 2016, o estado apresentou saldo líquido de -30.162 empregos formais.

Apesar desse resultado, os indicadores apresentaram tendência de melhora nos primeiros meses de 2017, com a volta da geração de empregos formais no setor capixaba. Mesmo que de forma não tão expressiva, a economia indica uma pequena melhora em relação aos dois anos que se antecederam.

É importante ressaltar que este estudo possui algumas limitações. Dentre elas, pode-se destacar: a pouca disponibilidade de dados devido à pequena amostra disponível; a falta de acesso a dados anteriores a janeiro de 2012, já que o IBGE só fornece dados a partir desse período; a não disposição de um modelo matemático que permitiria correlacionar com precisão as variáveis estudadas; a limitação que a simples comparação entre os indicadores no período oferece, não garantindo necessariamente a relação entre as variáveis estudadas.

Desta forma, sugere-se que novas pesquisas mais aprofundadas sobre o tema sejam realizadas, a fim de que se possa entender melhor a relação e os impactos da crise econômica sobre o setor de serviços no Espírito Santo. Outra sugestão é a utilização de modelos matemáticos que permitam, de fato, correlacionar as variáveis analisadas (ou até mesmo outras variáveis) de forma mais precisa e acertada.

\section{REFERÊNCIAS}

ALMEIDA, A. N.; SILVA, J. C. G. L.; ANGELO, H. Importância dos setores primário, secundário e terciário para o desenvolvimento sustentável. Revista Brasileira de Gestão e Desenvolvimento Regional. v. 9, n. 1, p. 146-162, 2013.

ANTUNES, R. Fenomenologia da crise brasileira. Lutas Sociais. v. 19, n. 35, p. 9-26, 2015.

BASTOS, S. Q. A.; PEROBELLI, F. S.; SOUZA, K. B. O dinamismo do setor de serviços e sua interação com o setor industrial: uma análise para a região sudeste no período pós Plano Real. Anais do XXXVI Encontro Nacional de Economia, 2008. 
BATTAGLIA, D.; BORCHARDT, M. Análise do processo de recuperação de serviços a partir das reclamações dos clientes: estudo de caso em três organizações. Produção, v. 20, n. 3, p. 455-470, 2010.

CAÇADOR, S. B.; GRASSI, R. A. Olhar crítico sobre o desempenho recente da economia capixaba: uma análise a partir da literatura de desenvolvimento regional e de indicadores de inovação. Revista Econômica do Nordeste, v. 40, n. 03, 2009.

CARDOSO, V. L.; ALMEIDA, E. Evolução e dinâmica espacial do setor de serviços e sua relação com o setor industrial. Revista de História Econômica \& Economia Regional Aplicada, v. 8, n. 15, 2013.

DIEESE. Departamento Intersindical de Estatística e Estudos Socioeconômicos. Boletim de conjuntura: crise econômica no Brasil. Subseção DIEESE. Out/2016. Disponível em:

<http://www.smabc.org.br/Interag/temp_img/\%7B4EC68B7E-4480-47F2-8B90-

B5B92A947FB0\%7D_Boletim\%20de\%20Conjuntura\%20Econ\%C3\%B4mica\%202016.pdf>. Acesso em: 10 maio 2017.

FITZSIMMONS, J. A. Administração de serviços: operações, estratégia e tecnologia da informação. 6. ed. Porto Alegre: Bookman, 2010.

FITZSIMMONS, J. A.; FITZSIMMONS, M. Administração de serviços: operações, estratégia e tecnologia da informação. 4. ed. Porto Alegre: Bookman, 2005.

FONSECA, J. J. S. Metodologia da pesquisa científica. Apostila. Fortaleza: UEC, 2002.

FRANCISCO, W. C. E. Economia do Espírito Santo. Disponível em <http://brasilescola.uol.com.br/brasil/aeconomia-espirito-santo.htm>. Acesso em: 11 mai. 2017.

GIL, A. C. Como elaborar projetos de pesquisa. 5. ed. São Paulo: Atlas, 2010.

GOVERNO DO ESTADO DO ESPÍRITO SANTO. Economia diversificada. Disponível em: <https://es.gov.br/economia-diversificada-2> Acesso em: 12 mai. 2017.

GUARDANI, F.; TEIXEIRA, M. L. M.; BIDO, D. S.; MAZZON, J. A. A relação entre valores, práticas organizacionais e confiança de clientes no setor de serviços. Produção, v. 23, n. 4, p. 806-817, 2013.

IBGE. Instituto Brasileiro de Geografia e Estatística. Pesquisa anual de serviços, v. 13, 2011. Disponível em: $<$ https://www.google.com.br/url?sa=t\&rct=j\&q=\&esrc=s\&source=web\&cd=2\&ved=0ahUKEwiJkI9noHUAhWKEZAKHdpOA4YQFggsMAE\&url=ftp\%3A\%2F\%2Fftp.ibge.gov.br\%2FComercio_e_Servicos\%2 FPesquisa_Anual_de_Servicos\%2Fpas2011\%2Fcomentarios2011.pdf\&usg=AFQjCNH8sMqpAzII3d6PFr1fvie2 WwYyCA\&sig2=qdrapZdnauZrJiYLR1pH0g\&cad=rja >. Acesso em: 09 mai. 2017.

IBGE. Instituto Brasileiro de Geografia e Estatística. Contas Regionais. 2017a. Disponível em: <http://seculoxx.ibge.gov.br/economicas/contas-nacionais> Acesso em: 10 jul. 2017.

IBGE. Instituto Brasileiro de Geografia e Estatística. Pesquisa mensal de serviços. 2017b. Disponível em: <http://www.ibge.gov.br/home/estatistica/indicadores/servicos/pms/default.shtm>. Acesso em: 01 mai. 2017. 
IBGE. Instituto Brasileiro de Geografia e Estatística. Pesquisa nacional por amostra de domicílios contínua. 2017c. Disponível em:

<http://www.ibge.gov.br/home/estatistica/indicadores/trabalhoerendimento/pnad_continua/primeiros_resultados/ default.shtm>. Acesso em: 28 abr. 2017.

IBGE. Instituto Brasileiro de Geografia e Estatística. Pessoal ocupado, por segmento de serviço, 2014. Disponível em http://brasilemsintese.ibge.gov.br/servicos/pessoal-ocupado-por-segmento-de-servico.html Acesso em: 08 mar. 2017.

IBGE. Instituto Brasileiro de Geografia e Estatística. Produto interno bruto dos municípios. Série Relatórios Metodológicos, v. 29, Rio de Janeiro. 2004.

IBGE. Instituto Brasileiro de Geografia e Estatística. Serviços. 2017d. Disponível em <http://brasilemsintese.ibge.gov.br/servicos.html> Acesso em: 08 mar. 2017. IJSN. Instituto Jones dos Santos Neves. Panorama econômico Espírito Santo: IV trimestre de 2016. Disponível em: <http://www.ijsn.es.gov.br/artigos/4759-panorama-economico-do-espirito-santo-4-trimestre-de2016>. Acesso em: 12 mai. 2017.

INCAPER. Instituto Capixaba de Pesquisa, Assistência Técnica e Extensão Rural. Síntese da produção agropecuária do Espírito Santo: 2014/2015. 2017. Disponível em: <http://biblioteca.incaper.es.gov.br/digital/bitstream/item/2699/1/BRT-sintese-2014-2015-final.pdf>. Acesso em: 20 mai. 2017.

JOHNSON, J. V. Services sector. Journal of Safety Research, v. 39, p. 191-194, 2008.

JOHNSTON, R; CLARK, G. Administração de operações e serviços. 1. ed. São Paulo: Atlas, 2011. MAGALHÃES, M. A.; TOSCANO, V. N. Assimetria e concentração: um estudo empírico da distribuição de investimentos previstos para o Estado do Espírito Santo, 2009-2014. Nova Economia. v. 22, n. 2, p. 333-377, 2012.

MOURA, T. L.; ALLIPRANDINI, D. H. Determinantes da qualidade em serviços de alimentação: o caso das empresas de refeições coletivas. XXIV Encontro Nacional de Engenharia de Produção. Florianópolis, SC. 2004.

PLANO DE DESENVOLVIMENTO DO ESPÍRITO SANTO. Plano de desenvolvimento do Espírito Santo: Espírito Santo 2030. 2013. Disponível em:

<https://sesp.es.gov.br/Media/sesp/Plano\%20ES\%202030/Plano\%20de\%20Desenvolvimento\%20ES\%202030.p df>. Acesso em: 20 mai. 2017.

PIGNATA, F. A.; CARVALHO, D. O. Efeitos da crise econômica no Brasil em 2015. Revista Eletrônica Diálogos Acadêmicos, v. 9, n. 2, p. 4-18, 2015.

POP-FLOREA, M.; HERMAN, E. Study on the need to increase the quality of the services sector in Romania. Scientific Bulletin of the Petru Maior University of Tirgu Mures, v. 6, p. 148-153, 2009. 
ROCHA, H. C.; MORANDI, A. M. Cafeicultura e grande indústria: a transição no Espírito Santo 1955-1985. 2 ed. Vitória: Espírito Santo em Ação, 2012.

RODRIGUES, A. Vitória é a melhor cidade para os negócios no Brasil, 2014. Disponível em <http://exame.abril.com.br/revista-exame/edicoes/1064/noticias/a-pequena-ilha-de-bons-negocios> Acesso em: 08 maio 2017.

SAMBATTI, A. P.; RISSATO, D. O setor terciário da economia: uma discussão teórica introdutória. II Seminário do Centro de Ciências Sociais Aplicadas - Cascavel. PR. 2003.

SILVA, C. N.; FILHO, N. M.; KOMATSU, B. Uma abordagem sobre o setor de serviços na economia brasileira. Policy Paper - Insper, n. 19, 2016.

SIMBRACS. Simpósio Brasileiro de Políticas Públicas para Comércio e Serviços. Setor terciário em destaque. Revista SIMBRACS. 2. ed., 2013. Disponível em: 〈http://www.mdic.gov.br/arquivos/dwnl_1414688276.pdf〉. Acesso em: 10 mai. 2017.

TRIVIÑOS, A. N. S. Introdução à pesquisa em ciências sociais: a pesquisa qualitativa em educação. São Paulo: Atlas, 1987. 